\title{
Irrigation-induced pollution of organochlorine pesticides and polychlorinated biphenyls in paddy field ecosystem of Liaohe River Plain, China
}

\author{
TENG Man ${ }^{1,2}$, ZHANG HaiJun $^{3}$, FU Qiang $^{2 *}$, LU XianBo $^{3}$, CHEN JiPing $^{3}$ \& WEI FuSheng ${ }^{1,2}$ \\ ${ }^{1}$ Research Center for Eco-Environmental Sciences, Chinese Academy of Sciences, Beijing 100085, China; \\ ${ }^{2}$ State Environmental Protection Key Laboratory for Quality Control of Environmental Monitoring, China National Environmental Monitoring \\ Center, Beijing 100012, China; \\ ${ }^{3}$ Dalian Institute of Chemical Physics, Chinese Academy of Sciences, Dalian 116023, China
}

Received November 19, 2012; accepted December 25, 2012; published online April 15, 2013

\begin{abstract}
In order to assess the influence of long-term irrigation of polluted river water on the ecological health of the rice fields in the low reach of Liaohe River Plain, a series of environmental samples and biological samples in rice fields, including sediments, paddy soils, mitten-handed crabs (Eriocheir sinensis), loaches (Misgurnus anguillicaudatu) and frog (Hoplobatrachus tigerinus), were collected from the area far away from industrial zones, and polychlorinated biphenyls (PCBs) and organochlorine pesticides (HCH, DDT, HCB and Mirex) were analyzed by high resolution gas chromatography coupled with high resolution mass spectrometry (HRGC/HRMS). The comparison of pollutant concentrations and profiles verified that the significant contribution of river water irrigation to PCBs contaminations in paddy soils and the mutual influence of organochlorine pesticide contamination between river sediments and paddy soils. Bioaccumulations of PCBs and organochlorine pesticides in mitten-handed crabs and loaches were site-specific, suggested that they were both the good indicators of ecosystem health. Mitten-handed crabs had the highest capacity to accumulate PCBs and organochlorine pesticides, and also they had the strong ability to degrade these pollutants in their bodies, especially for DDT and HCH. The biota-soil accumulation factors (BSAF) of $\Sigma$ HCH, $\Sigma$ DDT, Mirex, HCB and $\Sigma$ PCBs in mitten-handed crab were calculated to be 24.5, 15.3, 122.2, 28.1 and 54.6, respectively. In view of the strong bioaccumulation ability, the health risk should be concerned for the cultivation of mitten-handed crabs in paddy fields in the low reach of Liaohe River Plain.
\end{abstract}

organochlorine pesticides, polychlorinated biphenyls (PCBs), Liaohe River, pollution, irrigation

Citation: Teng M, Zhang H J, Fu Q, et al. Irrigation-induced pollution of organochlorine pesticides and polychlorinated biphenyls in paddy field ecosystem of Liaohe River Plain, China. Chin Sci Bull, 2013, 58: 1751-1759, doi: 10.1007/s11434-013-5815-1

Liaohe River is one of the most heavily polluted river in northeast China. In last decades, most of wastewaters in this river basin were not treated effectively, and they were discharged into the water system directly. Water qualities often exceeded the Category V standards of Surface Water Environmental Quality Standard of China, especially in dry season $[1,2]$. In the lower Liaohe River Plain, about 10 million acres of rice field was directly irrigated by the river water for a long time. Some pollutants in river water, especially

*Corresponding author (email: fuqiang@ @nemc.cn) the persistent organic pollutants (POPs), would be inevitably deposited in the paddy soil, absorbed by rice and accumulated by the biotic populations in paddy field, and finally transferred to the human body [3-5]. Therefore, it has been a big challenge to control the non-point source pollution of POPs in the rice field.

Organochlorine pesticides, such as dichlorodiphenyltrichloroethane (DDTs), hexachlorocyclohexane (HCHs), hexachlorobenzene (HCB) and Mirex, are ubiquitous anthropogenic contaminants and have been produced in a large amount in China [6]. Several studies have revealed the 
significant occurrence of DDTs and HCHs in the river water and sediment of Liaohe River [7-9]. Moreover, polychlorinated biphenyls (PCBs) have been widely used as flame retardants in China [10]. The high level pollution of PCBs has been found in the sediments from Liaohe River and Liaodong Bay of Bohai Sea [11,12]. In addition, a national survey indicated that PCB-TEQ in human milk from rural area of Liaohe River Basin was relatively higher [13]. However, little is known about the real pollution of organochlorine pesticides and PCBs in the rice ecosystem resulted from the irrigation of polluted river water.

Rice fields have been playing a great role in preserving biodiversity by providing habitats for many aquatic organisms, especially for amphibian, fish and invertebrate. Some monitoring studies have provided evidence that higher applications of pesticides can decrease the population of aquatic animals in rice field ecosystems $[14,15]$. Meanwhile, it was found that lethal and sublethal effects of organochlorine pesticides and PCBs are one of important causal factors for the decline in the size and number of amphibian populations [16,17]. During the last decade, there has been increased focus on the role of organochlorine pesticides and PCBs as retinoid (vitamin A) disrupters, and their effects on development, growth and sexual differentiation of organisms [18]. However, only a few studies focused on the bioaccumulation of these POPs in aquatic organisms from rice fields [4].

Cultivation of mitten-handed crab and loach in rice field has a long history in the lower Liaohe River Plain. In recent years, the local farmers have continuously raised the yield of cultivated mitten-handed crab and loach in order to meet the increase of commercial demand. It was estimated that the area of rice field cultivating mitten-handed crab has reached to about 1.6 million acres and the total yield was about 70 thousand tons in 2010. Mitten-handed crab and loach both have the habit to dig deep burrows in the mud, and thus they have the higher potential to accumulate the hydrophobic organic pollutants from the mud. Several studies indicated the site specific bioaccumulation of organochlorine pesticides and PCBs in crab, and suggested crab embryo as a good indicator of ecosystem health [19,20]. Therefore, a great concern should be paid to the health risk of consuming mitten-handed crab and loach cultivated in rice field.

The overall objective of the present study was to evaluate the impact of long-term river water irrigation on the pollution of organochlorine pesticides and PCBs in rice field ecosystem of the lower Liaohe River Plain. The specific objectives were to verify the correlation between river sediment contamination and paddy soil contamination, and characterize the bioaccumulation of organochlorine pesticides and PCBs in mitten-handed crab, loach, and frog in the rice field ecosystem. The obtained results will be of particular values for assessing the ecological risk and human health risk of POPs contamination in rice field ecosystem.

\section{Materials and methods}

\subsection{Sample collection and storage}

Daliao River is a major part of Liaohe River system and composed of Daliao River mainstream and its two main tributaries Hun River and Taizi River. During October 2010, 8 sediment samples and 11 paddy soil samples were taken from the low reach of Daliao River Basin. Sampling locations are shown in Figure 1. These sampling sites are far away from industrial zones in order to avoid the influence of point pollution. The sediment samples were taken at a $0-10 \mathrm{~cm}$ depth with a grab sampler or a stainless steel scoop. Five aliquots were taken from a 2-10 m radius from each site. Each paddy soil sample was comprised of top soil from a central point and top soils from four additional points located $10-20 \mathrm{~m}$ in the four primary directions from the central point. Meanwhile, biological samples, Chinese mitten-handed crab (Eriocheir sinensis H. Milne-Eswards), loach (Misgurnus anguillicaudatus), and frog (Hoplobatrachus tigerinus), were simultaneously collected from the local rice paddies with the help of local farmers using fishing net.

The collected samples were put into cleaned aluminum/ polyethylene bags with zippers, and then transported on ice to the laboratory. Sediment and paddy soil samples were first dried using a freezing dryer, and then ground to pass though a $1 \times 1 \mathrm{~mm}$ stainless steel sieve and fully homogenized. Biological samples were first checked weight and then soft parts were dissected. Mitten-handed crab samples included meat, embryo, and muscle tissues (in chelae and walking legs). Loach and frog samples consisted of flesh (musculature) and internal organs. The soft parts of biological sample were chopped and homogenized using a meat grinder, and then conducted freeze drying process. Finally, freeze-dried samples were all put into brown glass bottles and stored at $<4^{\circ} \mathrm{C}$.

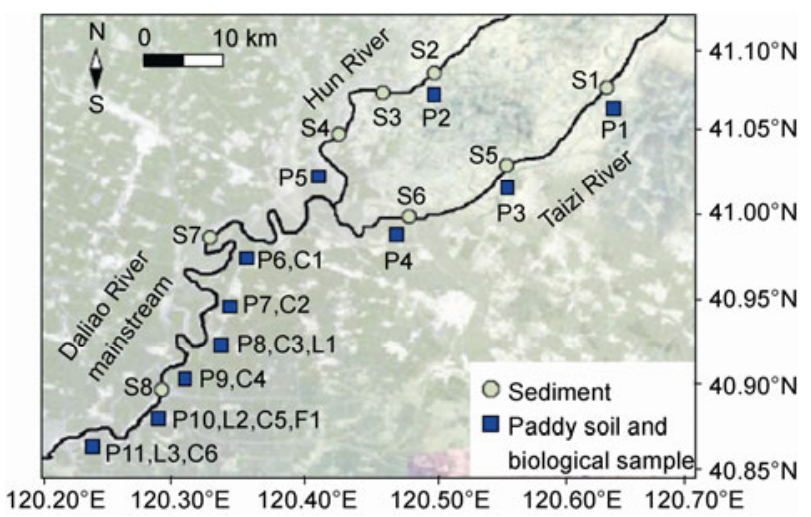

Figure 1 Map showing sampling locations in the lower reach of Liaohe River Plain, China. S: sediment; P: paddy soil; C: crab; L: loach; F: frog. 


\subsection{Standards and reagents}

The ${ }^{13} \mathrm{C}$-labeled stock solutions, including the surrogate solutions (EC-4937 and PCB 28 for PCBs analysis, and ES5349 for organochlorine pesticide analysis) as well as the injection internal standard solutions (EC-4979 for PCBs analysis, and EC-5350 for organochlorine pesticide analysis) were obtained from Cambridge Isotope Laboratory (Andover, MA, USA). The detailed information about the ${ }^{13} \mathrm{C}$ labeled stock solutions was listed in Table S1. Hexane and dichloromethane used for sample pretreatment were all pesticide analysis grade. Hexane was purchased from Merck (Germany), and dichloromethane was purchased from Tedia (USA). Basic alumina and silica gel were bought from ICN Medical (Germany). $\mathrm{Na}_{2} \mathrm{SO}_{4}$ was reagent grade and obtained from Aldrich. Before use, it was rinsed with hexane and then dried.

\subsection{Analytical methods}

Extraction for organochlorine pesticides and PCBs were simultaneously carried out. The $5 \mathrm{~g}$ of sediment and soil samples and about $1 \mathrm{~g}$ of biological samples were taken. These samples were freeze-dried and then extracted by Soxhlet apparatus with $250 \mathrm{~mL}$ of hexane/dichloromethane (50:50, v/v) for 24 h. ${ }^{13} \mathrm{C}_{12}$-labeled internal standards were spiked before Soxhlet extraction. After Soxhlet extraction, the extract was divided into two equal parts. One part is for PCBs analysis, and the other is for organochlorine pesticide analysis. The two parts of extract were both concentrated to $1 \mathrm{~mL}$ with a rotary evaporator. For biological samples, the concentrated extract was treated with $5 \mathrm{~mL}$ sulfuric acid $(98 \%)$ to remove lipid compounds.

For the determination of PCBs, a multi-layer silica gel column chromatograph was used for clean-up. The column was filled with $10 \mathrm{~g}$ anhydrous $\mathrm{Na}_{2} \mathrm{SO}_{4}$ at bottom, then $1 \mathrm{~g}$ silica gel, 3 g 30\% NaOH-silica gel, 1 g silica gel, 8 g 44\% $\mathrm{H}_{2} \mathrm{SO}_{4}$-silica gel, $1 \mathrm{~g}$ silica gel, $3 \mathrm{~g} 10 \% \mathrm{AgNO}_{3}$-silica gel, and finally $6 \mathrm{~g}$ anhydrous $\mathrm{Na}_{2} \mathrm{SO}_{4}$. Add $5 \mathrm{~g}$ copper powder on top of the multi-layer column, and PCBs were eluted with $120 \mathrm{~mL}$ of hexane. The elute was concentrated to $1 \mathrm{~mL}$, and then further cleaned up through an alumina column chromatograph. The column consisted of $5 \mathrm{~g}$ anhydrous $\mathrm{Na}_{2} \mathrm{SO}_{4}$ at bottom, then $10 \mathrm{~g}$ alumina, and $10 \mathrm{~g}$ anhydrous $\mathrm{Na}_{2} \mathrm{SO}_{4}$ on the top. The first elute by $40 \mathrm{~mL}$ hexane was discarded, and the target compounds were eluted in second fraction by $120 \mathrm{~mL} \mathrm{5 \%} \mathrm{dichloromethane} \mathrm{in} \mathrm{hexane.} \mathrm{For} \mathrm{the}$ determination of organochlorine pesticides, only a silica gel column chromatograph was used for the clean-up. The column was filled with $10 \mathrm{~g}$ anhydrous $\mathrm{Na}_{2} \mathrm{SO}_{4}, 8 \mathrm{~g}$ silica gel, and $10 \mathrm{~g}$ anhydrous $\mathrm{Na}_{2} \mathrm{SO}_{4}$. Organochlorine pesticides were eluted with $100 \mathrm{~mL}$ hexane/dichloromethane (50:50, $\mathrm{v} / \mathrm{v})$. The clean extract was transferred into a micro-vial gradually and evaporated to dryness with nitrogen stream. The $10 \mu \mathrm{L}$ tetradecane containing the injection internal standard was added to a micro-vial for instrumental analysis.

The purified extract was analyzed using an high resolution mass spectrometer (Autospec Ultima, Micromass, UK) interfaced with a gas chromatograph (Hewlett-Packard 6890 Plus, Palo Alto, CA, USA) (HRGC/HRMS). A capillary column DB-5MS $(60 \mathrm{~m} \times 0.25 \mathrm{~mm} \times 0.25 \mu \mathrm{m})$ was employed. Detailed instrumental conditions for PCBs have been given elsewhere [11]. For organochlorine pesticide analysis, splitless injection was employed. The GC oven was programmed as follows: initial temperature $80^{\circ} \mathrm{C}$, held for $1 \mathrm{~min}$, increased to $190^{\circ} \mathrm{C}$ at $30^{\circ} \mathrm{C} \mathrm{min}{ }^{-1}$, increased to $230^{\circ} \mathrm{C}$ at $2.5^{\circ} \mathrm{C} \mathrm{min}^{-1}$, increased to $260^{\circ} \mathrm{C}$ at $20^{\circ} \mathrm{C} \mathrm{min}^{-1}$ and held for $12 \mathrm{~min}$, and finally increased to $320^{\circ} \mathrm{C}$ at $20^{\circ} \mathrm{C}$ $\mathrm{min}^{-1}$ and held for $10 \mathrm{~min}$. The ion source was operated at $250^{\circ} \mathrm{C}$, the ionization current was $0.6 \mathrm{~mA}$, electron energy was $37 \mathrm{eV}$, ion accelerating voltage was $8 \mathrm{kV}$. The mass spectrometer was operated under positive EI conditions. SIM mode was used for quantification with the resolution of 6000 .

Extractable lipid content in biological sample was extracted by petroleum ether in triplicate. About $2 \mathrm{~g}$ of freezedried biological sample was wrapped in quantitative filter paper and then extracted for $6 \mathrm{~h}$ in a Soxhlet apparatus. The lipid fraction was estimated from the difference of weight, and it was used to calculate the lipid basis concentrations of PCBs and organochlorine pesticides in the biological sample. The total organic carbon (TOC) in sediment and paddy soil was analyzed with an elemental analyzer (Vario EL III). Prior to TOC analysis, the inorganic carbon in sediment and paddy soil was first removed used $0.1 \mathrm{~mol} \mathrm{~L}^{-1} \mathrm{HCl}$, and then the soil was dried at $105^{\circ} \mathrm{C}$ in a dry oven for $8 \mathrm{~h}$.

\section{$1.4 \mathrm{QA} / \mathrm{QC}$}

The threefold of signal-to-noise ratio was taken as the instrument detection limit (IDL). The IDL values ranged from 0.2 to $0.8 \mathrm{pg}$ for PCB congeners and from 0.1 to $0.5 \mathrm{pg}$ for organochlorine pesticides. The method detection limit (MDL) was obtained by measuring the spike, which was processed through the entire analytical method. The concentration of the spike should be generally 3 to 10 times of the expected MDL. The threefold of the standard deviation was taken as the MDL values. The MDL values ranged from $0.11 \mathrm{pg} \mathrm{g}^{-1}$ sample to $0.25 \mathrm{pg} \mathrm{g}^{-1}$ sample for PCBs and ranged from $0.12 \mathrm{pg} \mathrm{g}^{-1}$ sample to $0.43 \mathrm{pg} \mathrm{g}^{-1}$ sample for organochlorine pesticides. The recoveries of internal standard were all in the range of $35 \%$ to $140 \%$. Moreover, a method blank was run to check for interference and crosscontamination for every set of 10 samples.

\subsection{Statistical analysis}

Principal component analysis (PCA) was performed using SPSS 12.0 (Windows software package). Concentrations 
that were below the MDL were assigned a value zero before conducting PCA. The principal components were considered if their Eigenvalues were $>1$. The method of Varimax was selected for rotation in the PCA and 25 iterations were performed.

\section{Results and discussion}

\subsection{PCBs in sediments and paddy soils}

The analytical results of PCBs are listed in Table 1. The concentrations of $\Sigma$ PCBs (sum of indicator congeners and coplanar congeners) in the sediment samples ranged from 0.40 to $2.28 \mathrm{ng} \mathrm{g}^{-1}$ dry weight ( $\mathrm{dw}$ ), which were much higher than those $\left(0.07-0.32 \mathrm{ng} \mathrm{g}^{-1} \mathrm{dw}\right)$ in paddy soil samples. A heavy PCBs pollution was found in the sediments of Hun River (S2-S4), in which the $\mathrm{WHO}_{1998}$-TEQ values for PCBs were more than $3 \mathrm{ng} \mathrm{kg}^{-1} \mathrm{dw}$. Correspondingly, the paddy soils collected from the watershed area of Hun River also had the higher PCBs concentrations. Moreover, it was found that the $\Sigma$ PCBs concentrations in paddy soils significantly correlated with those in their adjacent sediments $(n=$ $7, P>0.95$ ) (Figure S1). These results indicated the significant contribution of river water irrigation to PCBs contaminations in paddy soils.

PCA was conducted for the indicator PCB congeners and dl-PCB congeners in sediments, paddy soils and biological samples (Tables S2 and S3). The results showed that the first principle component (PC1) and second principle component (PC2) accounted for $70.2 \%$ and $23.8 \%$ of total variability among the samples, respectively (Figure 2). The factor scores of all sediment samples and paddy soil samples on PC1 were between -2 and 0 , and they clustered together except for the sediment samples (S2-S4) from Hun River. The concentrations of PCB 77 and PCB 126 in sediment samples S2-S4 were relatively high (Table S2), and thus their factor scores were $>1.0$ on PC2. Correspondingly, their adjacent paddy soils S2 and S5 also had the relatively high concentrations of PCB 77 and PCB 126 although they were not clustered with sediment samples S2-S4 on the PCA score plot. The other sediment samples had the similar PCBs fingerprints to those of all paddy soils, characterized by the higher contents of PCB 28 and PCB 52 as well as the lower contents of PCB 169 and PCB 189 (Table S2). These analytical results of PCBs fingerprint further verified the irrigation-induced pollution of PCBs in paddy fields.

\subsection{Organochlorine pesticides in sediments and paddy soils}

The concentrations of $\Sigma$ DDT in the paddy soil samples were in the range of $1.60-21.55 \mathrm{ng} \mathrm{g}^{-1} \mathrm{dw}$ with an average value of $6.67 \mathrm{ng} \mathrm{g}^{-1} \mathrm{dw}$ (Table 1). Most of them was above the interim freshwater sediment quality guidelines $\left(6.15 \mathrm{ng} \mathrm{g}^{-1}\right.$ $\mathrm{dw}$ ) for SDDT in Canada, even exceeded the probable effect level (20.03 $\mathrm{ng} \mathrm{g}^{-1} \mathrm{dw}$ ), which implied that the incidence of adverse effects on biotic populations in rice fields was high. The average content of $\Sigma$ DDT in sediments was only a half of that in paddy soils; on the contrary, the average contents of $\mathrm{\Sigma HCH}$, Mirex and HCB in sediments were higher by 6.7, 7.4 and 0.4 times than those in paddy soils, respectively.

Mirex contents in paddy soils were relative low, and all lower than their adjacent sediments (Table S4), suggested that Mirex have been not widely used in the rice. However, the situations for DDT, HCH and HCB were complicated.

Table 1 Concentrations (range and mean in parenthesis) of organochlorine pesticides and PCBs in sediments, paddy soils, and biological samples from the lower reach of Liaohe River Plain

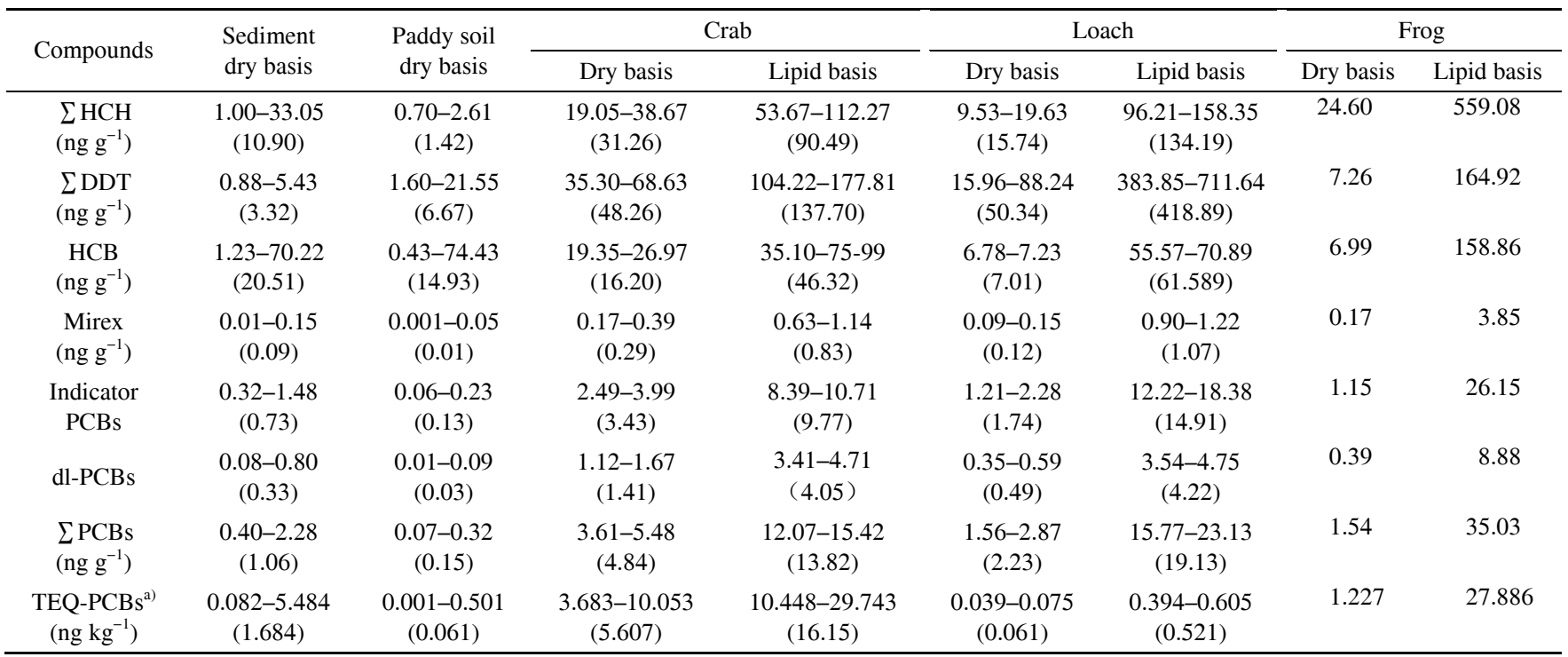

a) TEQ concentrations was calculated according to the $\mathrm{WHO}_{1998}$-TEF values of 12 dl-PCB congeners. 


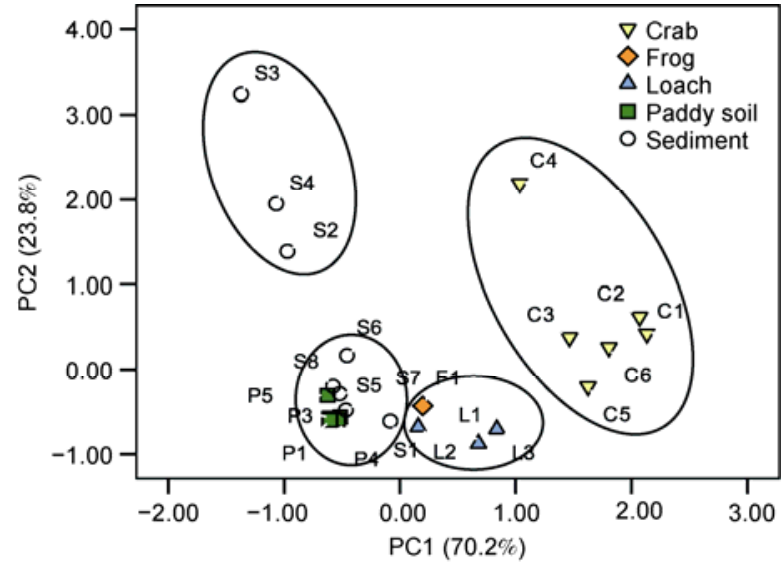

Figure 2 PCA score plot of PCB congeners in sediments, paddy soils, and biological samples from the lower reach of Liaohe River Plain.

These three kinds of organochlorine pesticides have been widely used in the rice fields. The histories of organochlorine pesticides application were different for the different rice fields, and thus the contents of DDT, HCH and HCB in different rice fields varied largely. In several rice fields that organochlorine pesticides have been heavily applied, the contents of DDT, $\mathrm{HCH}$ or $\mathrm{HCB}$ were much higher than those in their adjacent sediments, implied that the gross flow of organochlorine pesticides should be from rice fields to river water. On the contrary, the contents of DDT, $\mathrm{HCH}$ or HCB in most of rice fields were lower than those in their adjacent sediments, even lower by above 10 times individually, and therefore the river water irrigation should have the important contribution to the organochlorine pesticides contamination in rice fields.

PCA was also conducted for the organochlorine pesticides in sediment samples, paddy soil samples and biological samples (Tables S4 and S5). The first three PCs (Eigenvalue $>1$ ) accounted for $77.4 \%$ of total variability among the samples (26.8\% for PC1, 25.6\% for PC2, $25.0 \%$ for PC3) (Figure 3). Characteristic isomers with high factor loadings were: $\alpha-\mathrm{HCH}, \beta-\mathrm{HCH}$ and $\mathrm{HCB}$ for $\mathrm{PC} 1 ; o, p^{\prime}-\mathrm{DDD}$, $p, p^{\prime}-\mathrm{DDD}$ and $o, p^{\prime}-\mathrm{DDE}$ for PC2; and $\gamma$-HCH, $p, p^{\prime}-\mathrm{DDE}$ and Mirex for PC3. Despite of the huge difference among the organochlorine pesticide concentrations, all the sediment samples and paddy soil samples were clustered together on the PCA score plots of PC1 vs PC2 and PC1 vs PC3 except for the sediment samples (S2-S4) from Hun River. This result verified the mutual influence of organochlorine pesticide contamination between river sediments and paddy soils through river water irrigation and rice field drainage.

\subsection{Bioaccumulation of PCBs}

As shown in Table 1, PCBs concentrations in mitten-handed crabs, with the highest lipid contents, were relatively high. The $\mathrm{WHO}_{1998}$-TEQ concentrations of PCBs in mittenhanded crabs ranged from 3.683 to $10.053 \mathrm{ng} \mathrm{kg}^{-1} \mathrm{dw}$, one

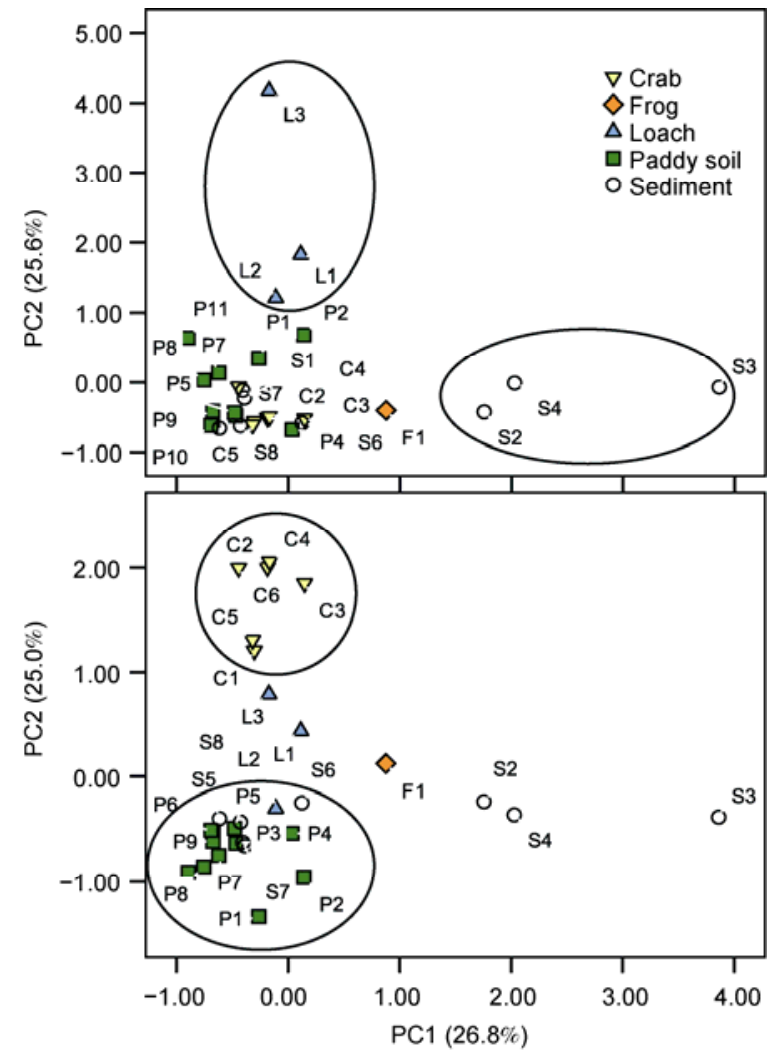

Figure 3 PCA score plot of the organochlorine pesticides $(\mathrm{HCH}, \mathrm{DDT}$, Mirex and HCB) in sediments, paddy soils, and biological samples from the lower reach of Liaohe River Plain.

of which was near to the new European maximum residue levels of PCDD/Fs in muscle meat of fish and fishery products (MRLs, 4 ng TEQ kg ${ }^{-1}$ wet weight (ww)) set in 2006. The average concentrations of $\sum$ PCBs in the mitten-handed crabs and loaches were $4.84 \mathrm{ng} \mathrm{g}^{-1} \mathrm{dw}$ and $2.23 \mathrm{ng} \mathrm{g}^{-1} \mathrm{dw}$, respectively; and the concentration of $\sum$ PCBs in frog was $1.54 \mathrm{ng} \mathrm{g}^{-1} \mathrm{dw}$. When calculating the lipid-basis concentrations of PCBs, frog was found to have the highest $\sum$ PCBs concentration, and loaches contained a little more $\sum$ PCBs than mitten-handed crabs.

In this study, the lipid-basis concentration of $\sum$ PCBs in frog was $35.03 \mathrm{ng} \mathrm{g}^{-1}$, which was lower than those (mean, $19.62 \mathrm{ng} \mathrm{g}^{-1} \mathrm{ww}$ ) in the adult green frogs collected from southwestern Michigan [21], and also lower than those (53-972 $\mathrm{ng} \mathrm{g}^{-1}$ lipid weight (lw)) in green frogs collected from the lower Fraser Valley of Canada [22]. Savage et al. [23] observed decreased activity levels in $R$. sylvatica tadpoles at tissue concentration of $5.966 \mu \mathrm{g} \mathrm{g}^{-1} \mathrm{wW}$ for $\sum$ PCBs but mortality was not significant different from controls at this concentration. PCBs concentration in the frog from low reach of Liaohe River Plain was far lower than this value. Therefore, there was little probability that the PCBs bioaccumulation caused the organ damage in the frog. Unfortunately, no published data about the PCBs concentrations in crabs and loaches were found to compare with our results. 
In the PCA score plot of PCB congeners, all mittenhanded crab samples were clustered together, while loach samples and frog sample were classified into one group (Figure 2), which suggested a species-related difference of PCBs bioaccumulation. Mitten-handed crabs had the higher contents of non-ortho PCBs (PCB 77, PCB 81, PCB 126 and PCB 169), whereas the contents of non-ortho PCBs in loaches were lower, especially PCB 126 and PCB 169 (< MDL values). This suggested that loaches should have the ability to degrade non-ortho PCBs. It was the lower concentration of PCB 126 with highest $\mathrm{WHO}_{1998}$-TEF that led to the tremendous decrease of PCB-TEQ concentrations in loaches compared with mitten-handed crabs.

The bioaccumulation of PCBs in mitten-handed crabs and loaches was found to be site-specific. The higher concentration of PCBs in paddy soil led to the higher accumulation of PCBs in the organism at the same site. In order to quantitatively describe the bioaccumulation ability of different organisms for PCBs, the biota-soil accumulation factors (BSAF) of PCB congeners for mitten-handed crab, loach and frog were calculated, and the results are shown in Table S6. The BSAF values of PCB congeners were in the range of 15.0-132.5 for mitten-handed crabs, 9.0-70.5 for loaches, and 8.8-46.9 for frog, respectively. The pentaPCBs and hexa-PCBs had the higher BSAF values. In view of the lipophilic property of PCBs, the relationship between BSAF values and $K_{\mathrm{OW}}$ values [24] was explored. It was found that BSAF values of PCBs for mitten-handed crabs and loaches both exponentially increased with the increase of $K_{\text {Ow }}$ values from 5.6 to 6.8 (Figure 4). However, BSAF values of PCBs showed a decreasing tendency with the continuous increase of $K_{\mathrm{OW}}$ values.

\subsection{Bioaccumulation of organochlorine pesticides}

The PCA results indicated an obvious interspecies difference in bioaccumulation of organochlorine pesticides. As shown in Figure 3, three loach samples were clustered together on the PCA score plot of PC1 vs PC2, and their

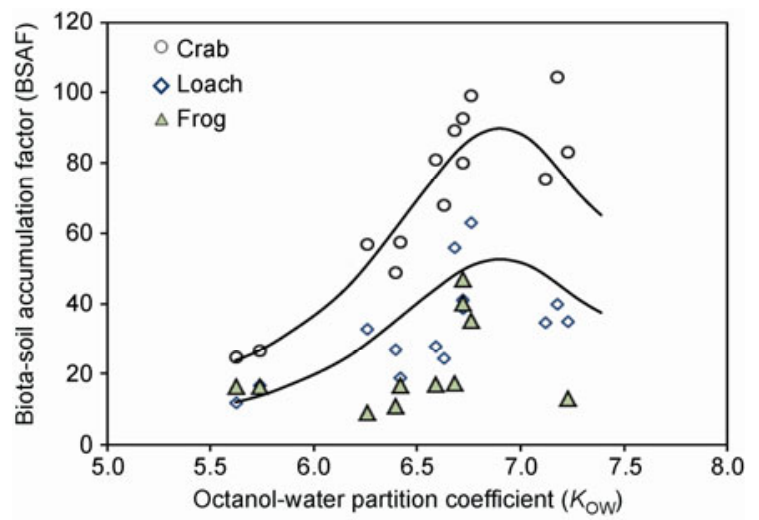

Figure 4 The relationship between biota-soil accumulation factors of PCB congeners and their $K_{\mathrm{OW}}$ values. factor scores were $>1.0$ on $\mathrm{PC} 2$ due to the higher contents of $o, p^{\prime}$-DDD, $p, p^{\prime}$-DDD and $o, p^{\prime}$-DDE. Meanwhile, six mitten- handed crab samples were classified into one group, and their factor scores were $>1.0$ on PC3 due to the higher contents of $\gamma$-HCH, $p, p^{\prime}$-DDE and Mirex. Frog sample had the relatively high contents of $\alpha-\mathrm{HCH}$ and $\beta-\mathrm{HCH}$, and thus it was separated from the both groups of mitten-handed crabs and loaches on the PCA score plot.

The dry-weight concentrations of $\sum$ DDT in mittenhanded crabs ranged from 35.30 to $68.63 \mathrm{ng} \mathrm{g}^{-1}$. These values were comparable to those in loaches (15.96-88.24 ng $\mathrm{kg}^{-1} \mathrm{dw}$ ). However, the average lipid-basis concentration of $\sum$ DDT in loaches (418.89 $\mathrm{ng} \mathrm{g}^{-1}$ ) was higher by 2.2 times than that in mitten-handed crabs $\left(137.70 \mathrm{ng} \mathrm{g}^{-1}\right)$. Compared with published data, the total DDT concentrations in mitten-handed crabs from this study were comparable to those (mean, $12.8 \mathrm{ng} \mathrm{g}^{-1}$ ww) in sea crabs (Scylla serrata and Ovalipes punctatus) collected from South China [25], but were less than those in river crabs (526-821 $\mathrm{ng} \mathrm{g}^{-1} \mathrm{lw}$ ) collected from Qiangtang River of China [26], and also less than those in most of sand crabs (43-13000 $\left.\mathrm{ng} \mathrm{g}^{-1} \mathrm{lw}\right)$ along the California coast $[20,27,28]$. Moreover, the total DDT contents in loaches determined in this study were found to be less than those (125-127 $\mathrm{ng} \mathrm{g}^{-1}$ ww) in rice field eel (Monopterus albus) obtained from Hong Kong markets [29].

The lipid-basis concentration of $\sum$ DDT in frog (164.92 $\mathrm{ng} \mathrm{g}^{-1}$ ) was similar to those in mitten-handed crabs. The total concentration of DDT in frog from the present study was at middle level among the reported concentration range of $\sum$ DDT (10-1000 $\left.\mathrm{ng} \mathrm{g}^{-1} \mathrm{lw}\right)$ detected in frogs and their eggs from other areas of the world [21,22,30-33]. The lowest $\sum$ DDT concentration that has a toxic effect on amphibians was reported to be $2400 \mathrm{ng} \mathrm{g}^{-1}$ ww in common frog $(R$. temporaria) tadpoles [16]. Therefore, there was little probability that the DDT bioaccumulation caused the organ damage in the frog from these test rice fields.

DDT can be reductively dechlorinated to DDD or dehydrochlorinated to DDE by organisms and the metabolites are more persistent than the parent compound. Therefore, the ratio of $(\mathrm{DDD}+\mathrm{DDE}) / \sum \mathrm{DDT}$ is a good indicator of DDT biodegradation [19]. In this study, mitten-handed crabs had the highest average ratio of (DDD+DDE)/ $\sum$ DDT of 0.97 , followed by loaches (0.91) (Figure 5). The ratio of (DDD+DDE)/ $\sum$ DDT in frog was 0.78 , which was higher than the average ratio of (DDD+DDE)/ $\sum$ DDT in paddy soils (0.57). The $p, p^{\prime}$-DDE was the most DDT metabolite in all biological samples, especially in mitten-handed crabs. These results suggested that mitten-handed crabs had a larger capacity to degrade DDT to DDE.

The lipid-basis concentrations of $\sum \mathrm{HCH}, \mathrm{HCB}$ and Mirex in mitten-handed crabs were in the ranges of 53.67$112.27,35.10-75.99$, and $0.63-1.4 \mathrm{ng} \mathrm{g}^{-1}$, respectively. These values were similar to the corresponding data determined in loaches (Table 1). Compared with published data, 


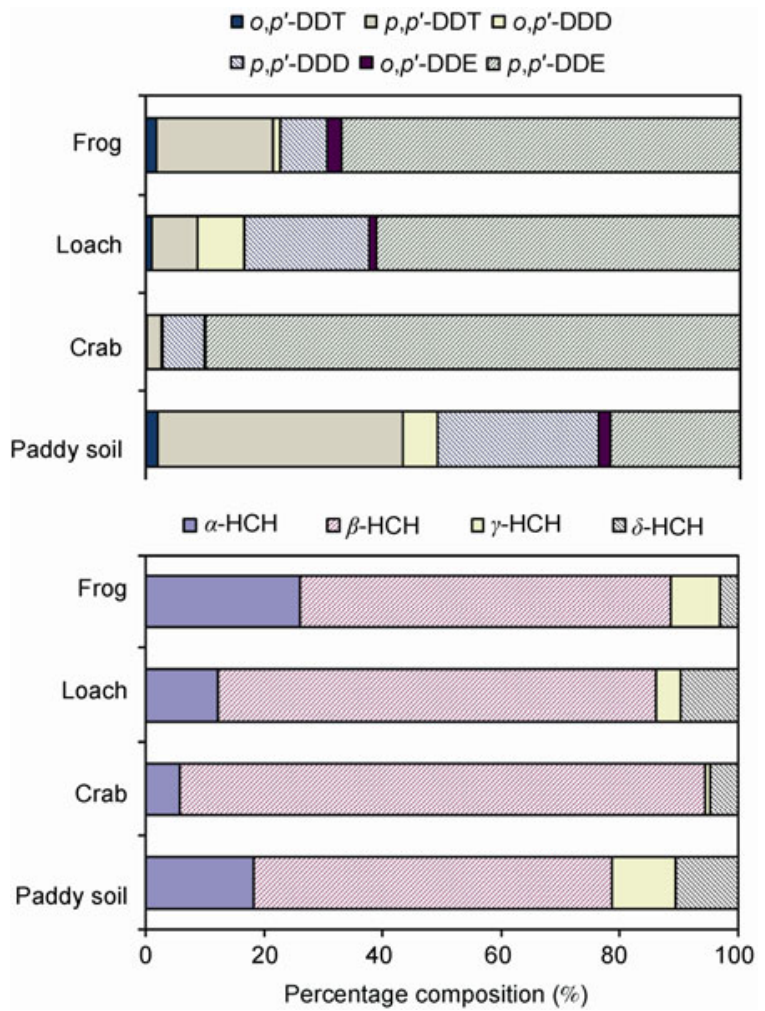

Figure 5 Percentage compositions of DDT isomers and $\mathrm{HCH}$ isomers in paddy soils and biological samples from the lower reach of Liaohe River Plain.

the total concentrations of $\mathrm{HCH}$ in mitten-handed crabs from this study was less than those in the river crab (643 $\mathrm{ng} \mathrm{g}^{-1} \mathrm{lw}$ ) from Qiantang River of China [26], and also much less than those in mangrove crab $\left(62 \mathrm{ng} \mathrm{g}^{-1} \mathrm{ww}\right)$ from South India [19]. However, the mitten-handed crabs has the higher contents of HCB compared with mangrove crab from South India [19].

Frog had much higher lipid-basis concentrations of $\sum \mathrm{HCH}, \mathrm{HCB}$ and Mirex. The lipid-basis concentration in frog was $559.08 \mathrm{ng} \mathrm{g}^{-1}$ for $\sum \mathrm{HCH}, 158.86 \mathrm{ng} \mathrm{g}^{-1}$ for $\mathrm{HCB}$, and $3.85 \mathrm{ng} \mathrm{g}^{-1}$ for Mirex, respectively. It was found that the total concentration of $\mathrm{HCH}$ in frog from the present study exceeded the reported concentrations of $\Sigma \mathrm{HCH}$ detected in tissues of frogs from Thermaikos Gulf wetlands of Greece [30] and from southwestern Michigan [21]. Meanwhile, the HCB concentration in frog was also found to be much more than those in the tissues of and eggs of frogs from the lower Fraser Valley of Canada [22,31].

Regarding percentage composition of $\mathrm{HCH}$ isomers, $\beta$-HCH concentration was highest in all biological samples. In biotic bodies $\beta-\mathrm{HCH}$ is more stable than $\alpha-\mathrm{HCH}$ and $\gamma-\mathrm{HCH}$ to enzymatic degradation [19], and thus the ratio of $\beta-\mathrm{HCH} / \gamma-\mathrm{HCH}$ can reflect the degradation in organisms. As shown in Figure 5, mitten-handed crabs had the surprisingly high average ratio of $\beta-\mathrm{HCH} / \gamma-\mathrm{HCH}$ of 95.0 , which was 5.3 times as much as in loaches. These results implied that mitten-handed crabs had the strong ability to degrade $\mathrm{HCH}$ in their bodies. Compared with mitten-handed crabs and loaches, the ratio of $\beta-\mathrm{HCH} / \gamma-\mathrm{HCH}$ in frog (7.7) was very low, which was near to the values in paddy soils (mean, 5.6).

The site-specific bioaccumulation of organochlorine pesticides was also found in mitten-handed crabs and loaches. The concentrations of $\sum \mathrm{DDT}, \sum \mathrm{HCH}, \mathrm{HCB}$ and Mirex in mitten-handed crabs and loaches all presented the increasing tendency with the increase of their concentrations in the local paddy soils. The biota-soil accumulation factor (BSAF) for each isomer of organochlorine pesticides in mittenhanded crab, loach and frog were calculated, and the results are shown in Table 2. Mitten-handed crabs had the higher lipid content, and thus the BSAF values of $\sum \mathrm{HCH}, \mathrm{HCB}$ and Mirex for mitten-handed crabs were significantly larger than those for loaches. However, The BSAF values of $\sum$ DDT for mitten-handed crabs were almost identical to those for loaches, mainly due to the significant biodegradation of DDT isomers in mitten-handed crabs.

\section{Conclusions}

This study indicated a significant contribution of long-term irrigation of river water to the contamination of PCBs in paddy soils from the lower reach of Liaohe River Plain and the mutual influence of organochlorine pesticide contamination between river sediments and paddy soils through river water irrigation and rice field drainage. Meanwhile, it also indicated the species-specific and site-specific bioaccumulation of PCBs and organochlorine pesticides. Mitten-handed crabs, with the higher lipid content, had the largest capacity to accumulate PCBs, DDT, HCH, HCB and Mirex, and also they had the strong ability to degrade these pollutants in their bodies, especially for DDT and $\mathrm{HCH}$. Compared with the published data, the levels of organochlorine pesticides in mitten-handed crabs, loaches and frog were all not much higher, which implied that organochlorine pesticides originated from the previous application and long-term irrigation of polluted river water did not pose a serious risk to the ecological safety of rice fields. However, the TEQ concentrations of PCBs in test mitten-handed crabs were found to be a little higher and one of them was near to the new European maximum residue levels of PCDD/Fs in muscle meat of fish and fishery products. Therefore, the ecological risk and health risk should be concerned for the

Table 2 Biota-soil accumulation factors (BSAF) of organochlorine pesticides for crab, loach and frog

\begin{tabular}{lccr}
\hline & Crab & Loach & Frog \\
\hline$\Sigma$ HCH & $24.5 \pm 4.6$ & $11.9 \pm 2.1$ & 24.6 \\
$\Sigma$ DDT & $15.3 \pm 12.4$ & $11.3 \pm 9.9$ & 7.2 \\
Mirex & $122.2 \pm 10.7$ & $53.5 \pm 2.2$ & 105.8 \\
HCB & $28.1 \pm 4.2$ & $14.1 \pm 2.0$ & 14.5 \\
$\Sigma$ PCBs & $54.6 \pm 9.9$ & $28.1 \pm 6.9$ & 19.9 \\
\hline
\end{tabular}


cultivation of mitten-handed crabs in paddy soils from low reach of Daliao River Plain.

The authors express their gratitude to the skillful technical assistance of $S$. Wang with the sample preparation, and X. Zhang with the associated mass spectrometric determinations. This work was supported by the National Natural Science Foundation of China (21077102), the National Basic Research Program of China (2009CB421602), and the Special Environmental Protection Foundation for Public Welfare Project (201209016).

1 Jia Y X, Ju F H. Water environmental quality and pollution characteristics in Liaohe waters (in Chinese). Environ Monit China, 1999, 15: 51-53

2 Ministry of Environmental Protection of the People's Republic of China. Environmental Quality Standard for Surface Water (GB 3838-2002). 2002

3 Zhang H, Ni Y, Chen J, et al. Polychlorinated dibenzo-p-dioxins and dibenzofurans in soils and sediments from Daliao River Basin, China. Chemosphere, 2008, 73: 1640-1648

4 Roche H, Vollaire Y, Martin E, et al. Rice fields regulate organochlorine pesticides and PCBs in lagoons of the Nature Reserve of Camargue. Chemosphere, 2009, 75: 526-533

5 Johansen H R, Alexander J, Rossland O J, et al. PCDDs, PCDFs, and PCBs in human blood in relation to consumption of crabs from a contaminated fjord area in Norway. Environ Health Persp, 1996, 104: 756-764

6 Hua X M, Shang Z J. Production and application of pesticides and factor analysis for their pollution in environment in China (in Chinese). Adv Environ Sci, 1996, 2: 33-45

7 Zhang X F, Quan X, Chen J W, et al. Investigation of polychlorinated organic compounds (PCOCs) in middle and lower reaches of Liaohe River (in Chinese). China Environ Sci, 2000, 20: 31-35

8 Quan X, Martens D, Chen J W, et al. Pentachlorobenzen, hexachlorobenzene, pentachloroanisole, $\mathrm{HCHs}$, DDTs and PCBs in the Liaohe River. In: Gawlik B M, Platzer B, Muntau H, eds. Freshwater Contamination in China-Current Topics of Research. Luxembourg: European Commission, 2001. 97-112

9 Wang H, He M, Lin C, et al. Distribution characteristics of organochlorine pesticides in river surface sediments in Song-Liao Watershed. Chin J Appl Ecol, 2007, 18: 1523-1527

10 Ministry of Environmental Protection of the People's Republic of China. National Implementation Plan for the Stockholm Convention on Persistent Organic Pollutants. 2007

11 Zhang $\mathrm{H}$, Zhao X, Ni Y, et al. PCDD/Fs and PCBs in sediments of the Liaohe River, China: Levels, distribution, and possible sources. Chemosphere, 2010, 79: 754-762

12 Zhao X, Zhang H, Fan J, et al. Dioxin-like compounds in sediments from the Daliao River Estuary of Bohai Sea: Distribution and their influencing factors. Mar Pollut Bull, 2011, 62: 918-925

13 Li J, Zhang L, Wu Y, et al. A national survey of polychlorinated dioxins, furans (PCDD/Fs) and dioxin-like polychlorinated biphenyls (dl-PCBs) in human milk in China. Chemosphere, 2009, 75: 12361242

14 Nurhasan M. Nutritional composition of aquatic species in laotian rice field ecosystems; Possible impact of reduced biodiversity. Dissertation for the Master's Degree. Norway: University of Troms $\emptyset$, 2008
15 Collins J P, Storfer A. Global amphibian declines: Sorting the hypotheses. Divers Distrib, 2003, 9: 89-98

16 Cooke A S. The effects of DDT, dieldrin and 2,4-D on amphibian spawn and tadpoles. Environ Pollut, 1972, 3: 51-68

17 Hayes T B. Endocrine disruption in amphibians. In: Sparking D W, Linder G, Bishop C A, eds. Ecotoxicology of Amphibians and Reptiles. Pensacola: Soc EnvironToxic Chem, 2000. 904

18 Leiva-Presa A, Mortensen A S, Arukwe A, et al. Altered hepatic retinol and CYP26 levels in adult European common frogs (Rana temporaria) exposed to $p, p^{\prime}$-DDE. Mar Environ Res, 2006, 62: S10-S15

19 Ramesh A, Tanabe S, Kannan K, et al. Characteristic Trend of persistent organochlorine contamination in wildlife from a tropical agricultural watershed, South India. Arch Environ Toxicol Chem, 1992, 23: $26-36$

20 Smalling K L, Morgan S, Kuivila K K. Accumulation of current-use and organochlorine pesticides in crab embryos from Northern California, USA. Environ Toxicol Chem, 2010, 29: 2593-2599

21 Gillilland C D, Summer C L, Gillilland M G, et al. Organochlorine insecticides, polychlorinated biphenyls, and metals in water, sediment, and green frogs from southwestern Michigan. Chemosphere, 2001, 44: 327-339

22 Loveridge A R, Bishop C A, Elliott J E, et al. Polychlorinated biphenyls and organochlorine pesticides bioaccumulated in green frogs, Rana clamitans, from the lower fraser valley, British Columbia, Canada. B Environ Contam Tox, 2007, 79: 315-318

23 Savage W K, Quimby F W, DeCaprio A P. Lethal and sublethal effects of polychlorinated biphenyls on Rana sylvatica tadpoles. Environ Toxicol Chem, 2002, 21: 168-174

24 Zhou W, Zhai Z, Wang Z, et al. Estimation of n-octanol/water partition coefficients $\left(K_{\mathrm{OW}}\right)$ of all $\mathrm{PCB}$ congeners by density functional theory. J Mol Struc: Theochem, 2005, 755: 137-145

25 Guo J, Wu F, Shen R, et al. Dietary intake and potential health risk of DDTs and PBDEs via seafood consumption in South China. Ecotox Environ Safe, 2010, 73: 1812-1819

26 Zhou R, Zhu L, Chen Y, et al. Concentrations and characteristics of organochlorine pesticides in aquatic biota from Qiantang River in China. Environ Pollut, 2008, 151: 190-199

27 Dugan J E, Ichikawa G, Crane D B, et al. Monitoring of coastal contaminants using sand crabs. Final Report. San Luis Obispo, CA: Central Coast Regional Water Quality Control Board. 2004

28 Burnett R. DDT residues: Distribution of concentration in Emerita analoga along the coast of California. Science, 1971, 174: 606-608

29 Cheung K C, Leung H M, Kong K Y, et al. Residual levels of DDTs and PAHs in freshwater and marine fish from Hong Kong markets and their health risk assessment. Chemosphere, 2007, 66: 460-468

30 Albanis T A, Hela D, Papakostas G, et al. Concentration and bioaccumulation of organochlorine pesticide residues in herons and their prey in wetlands of Thermaikos Gulf, Macedonia, Greece. Sci Total Environ, 1996, 182: 11-19

31 Russell R W, Gillan K A, Haffner G D. Polychlorinated biphenyls and chlorinated pesticides in southern Ontario, Canada, green frogs. Environ Toxicol Chem, 1997, 16: 2258-2263

32 de Solla S R, Bishop C A, Pettit K E, et al. Organochlorine pesticides and polychlorinated biphenyls (PCBs) in eggs of red-legged frogs (Rana aurora) and northwestern salamanders (Ambystonma gracile) in an agricultural landscape. Chemosphere, 2002, 46: 1027-1032

33 Kadokami K, Takeishi M, Kuramoto M, et al. Maternal transfer of organochlorine pesticides, polychlorinated dibenzo- $p$-dioxins, debenzofurans, and coplanar polychlorinated biphneyls in frogs to their eggs. Chemosphere, 2004, 57: 383-389

Open Access This article is distributed under the terms of the Creative Commons Attribution License which permits any use, distribution, and reproduction in any medium, provided the original author(s) and source are credited. 


\section{Supporting Information}

Table S1 The detailed information about the ${ }^{13} \mathrm{C}$-labeled standard solutions of PCBs $\left({ }^{13} \mathrm{C}_{12}, 99 \%\right)$ and organochlorine pesticides

Table S2 Concentrations of PCBs in the sediments and paddy soils from the low reach of Liaohe River Plain, China

Table S3 Concentrations of PCBs in the fish, crab and frog from the rice fields

Table S4 Concentrations of organochlorine pesticides in the sediments and paddy soils from the low reach of Liaohe River Plain, China

Table S5 Concentrations of organochlorine pesticides in the fish, crab and frog from the rice fields

Table S6 Biota-soil accumulation factors (BSAF) of PCB congeners and organochlorine pesticides (DDT, HCH, Mirex and HCB) for crab, loach and frog

Figure S1 Pattern distribution of PCB congeners in sediments, paddy soils, and biological samples from the low reach of the Liaohe River Plain, China.

Figure S2 The correlation of $\Sigma$ PCBs concentrations in paddy soils with those in their adjacent sediments.

The supporting information is available online at csb.scichina.com and www.springerlink.com. The supporting materials are published as submitted, without typesetting or editing. The responsibility for scientific accuracy and content remains entirely with the authors. 